\title{
Práticas Multidisciplinares: Atividades Lúdicas e Tecnologia Digital aliada ao estudo de Artes e Geometria
}

\author{
Prácticas Multidisciplinares: Actividades Lúdicas y la Tecnología Digital \\ aliada para el estudio de Artes y Geometría
}

\author{
Multidisciplinary Practices: Play Activities and Digital Technology allied \\ to the study of Arts and Geometry
}

Raquel Silveira da Silva ${ }^{1}$

Vanda Leci Bueno Gautério2

\begin{abstract}
Resumo
A Geometria, tem se apresentado como uma ferramenta importante para a compreensão dos conceitos desenvolvidos nas aulas de Matemática e quando aliada ao uso pedagógico dos materiais concretos e das tecnologias digitais tem potencializado a interação, visualização e compreensão dos conceitos em estudo. Este trabalho de caráter multidisciplinar, tem como objetivo trazer uma análise quantitativa a partir dos pressupostos teóricos de D’Ambrósio (1996), Lorenzato (2012), Prensky (2001) e Mendes (2009) para discutirmos, refletirmos e ressignificarmos os conceitos geométricos de prática pedagógica multidisciplinar desenvolvida por professores da rede pública da cidade de Rio Grande/RS, que trabalharam com Ensino por Projetos com o intuito de explorar conceitos geométricos como: ponto, reta, plano, vértices, diagonais e classificação dos ângulos, além de simetria e isometria, oportunizando o desenvolvimento da criatividade, percepção espacial e visual, capacidade de abstração e imaginação. Assim, fizeram a articulação do ensino de Matemática aos saberes de Artes realizando a construção do Tangram com dobradura, o estudo das obras Maurits Cornelis Escher, e ainda exploraram o software Geogebra. A experiência mostrou que quando os estudantes são desafiados a operar com os conceitos, os compreendem mais facilmente e as atividades lúdicas desenvolvem a autonomia, a criticidade, a cooperação e colaboração, levam os estudantes a estabelecer relações entre o que já sabem e o que desejam conhecer.
\end{abstract}

Palavras-chave: Ensino de Geometria; Geogebra, Material Concreto; Práticas Multidisciplinares; Projeto de Ensino.

\section{Resumen}

La Geometría, se ha presentado como una herramienta importante para la comprensión de los conceptos desarrollados en las clases de Matemáticas y cuando aliado al uso pedagógico de los materiales concretos y de las tecnologías digitales ha potenciado la interacción, visualización y comprensión de los conceptos en estudio. Este trabajo de carácter multidisciplinario, tiene como objetivo traer un análisis cuantitativo a partir de los presupuestos teóricos de D'Ambrosio (1996), Lorenzato (2012), Prensky (2001) y Mendes (2009) para discutir, reflexionar y resignificar los conceptos geométricos la práctica pedagógica multidisciplinaria desarrollada por profesores de la red pública de la ciudad de Rio Grande / RS, que trabajaron con Enseñanza por Proyectos con el propósito de explorar conceptos geométricos como: punto, recta, plano, vértices, diagonal y clasificación de los ángulos, además de simetría y simetría y en el sentido de que el desarrollo de la creatividad, la percepción

\footnotetext{
${ }^{1}$ Mestre em Educação em Ciências pelo Programa de Pós-Graduação em Educação em Ciências: Química da Vida e Saúde- PPGEC; Universidade Federal do Rio Grande-FURG; Rio Grande/RS, Brasil; Email: raquelsds2013@gmail.com.

${ }^{2}$ Doutora em Educação em Ciências pelo Programa de Pós-Graduação em Educação em Ciências: Química da Vida e Saúde- PPGEC; Universidade Federal do Rio Grande- FURG;Rio Grande/RS,Brasil; Email: vandaead@gmail.com.
} 
espacial y visual, la capacidad de abstracción e imaginación. Así, hicieron la articulación de la enseñanza de Matemáticas a los saberes de Artes realizando la construcción del Tangram con plegado, el estudio de las obras Maurits Cornelis Escher, y aún exploraron el software Geogebra. La experiencia mostró que cuando los estudiantes son desafiados a operar con los conceptos, los comprenden más fácilmente y las actividades lúdicas desarrollan la autonomía, la criticidad, la cooperación y la colaboración, llevan a los estudiantes a establecer relaciones entre lo que ya saben y lo que desean saber.

Palabras clave: Enseñanza de Geometría; Geogebra, Material Concreto; Prácticas multidisciplinares; Proyecto de Enseñanza.

\begin{abstract}
Geometry has been presented as an important tool for understanding the concepts developed in Mathematics classes and when allied to the pedagogical use of concrete materials and digital technologies has potentiated the interaction, visualization and understanding of the concepts under study. This work of multidisciplinary character, aims to bring a quantitative analysis from the theoretical assumptions of D'Ambrósio (1996), Lorenzato (2012), Prensky (2001) and Mendes (2009) to discuss, reflect and re-signify the geometric concepts of multidisciplinary pedagogical practice developed by teachers of the public network of the city of Rio Grande / RS, who worked with Teaching by Projects with the intention of exploring geometric concepts such as: point, line, plane, vertices, diagonals and classification of angles, besides symmetry and isometry, allowing the development of creativity, spatial and visual perception, capacity for abstraction and imagination. Thus, they made the articulation of the teaching of Mathematics to the knowledge of Arts realizing the construction of the Tangram with folding, the study of the works Maurits Cornelis Escher, and still they explored the software Geogebra. Experience has shown that when students are challenged to operate with concepts, understand them more easily and play activities develop autonomy, criticality, cooperation and collaboration, they lead students to establish relationships between what they already know and what they want to know.
\end{abstract}

Keywords: Geometry Teaching; Geogebra, Concrete Material; Multidisciplinary Practices; Teaching Project.

\title{
1 Introdução
}

Atualmente, com a evolução tecnológica, social e cultural, as instituições de ensino têm buscado diferentes metodologias para aproximar os conteúdos abordados em sala de aula a realidade dos discentes. Nesse processo, uma das alternativas tem sido o desenvolvimento de Projetos de Ensino que envolvam práticas multidisciplinares, articulando os saberes de diversas áreas do conhecimento e assim oportunizando a construção do conhecimento.

Estudos (Nogueira, 2015, Fazenda, 2013) mostram que a multidisciplinaridade nos possibilita a justaposição entre vários conceitos, e até mesmo, disciplinas que passam a conversar sobre um mesmo tema ou problema sem estabelecer relações entre os profissionais de cada área. A prática multidisciplinar consiste em propor atividades que as diferentes áreas do ensino possam dialogar sobre uma mesma temática e assim possibilitar que os alunos ampliem o seu conhecimento.

Entretanto, o que vemos, por muitas vezes, é um ensino escolar descontextualizado, sem uma metodologia de ensino definida e/ou aproximação das áreas do conhecimento, o que ocasiona a falta de interesse pela aprendizagem, pelo espaço escolar, reprovação e evasão, por não conseguirem compreender as relações entre os conceitos vistos na escola relacionados com o seu dia a dia. 
Um exemplo é o estudo da Geometria que, normalmente, é realizado de forma isolada dos demais conceitos matemáticos e limitado apenas ao último trimestre do ano letivo, uma vez que nos livros didáticos alguns autores colocam estudo destes conceitos nos últimos capítulos de suas publicações (ROGENSKI, PEDROSO, 2014).

Diante desta problemática, apresentamos uma prática pedagógica multidisciplinar desenvolvida por professores da rede pública da cidade de Rio Grande/RS, que trabalharam com Projetos de Ensino (PORTES, 2010), as quais objetivaram explorar conceitos geométricos como: ponto, reta, plano, vértices, diagonais e classificação dos ângulos, além de simetria e isometria, oportunizando o desenvolvimento da criatividade, percepção espacial e visual, capacidade de abstração e imaginação.

A prática pedagógica foi desenvolvida com 18 estudantes, do $8^{\circ}$ ano, de uma escola municipal, de Rio Grande/ RS, no segundo semestre de 2018, no qual foram desafiados a explorar conceitos geométricos como: ponto, reta, plano, vértices, diagonais e classificação dos ângulos, além de simetria e isometria por meio de pesquisas na Web 2.03 e nos livros didáticos. Para isso, foi realizado a construção do Tangram com dobradura ${ }^{3}$, o estudo e releitura das obras Maurits Cornelis Escher, e ainda exploraram o software Geogebra.

Para o desenvolvimento da atividade foram realizados seis encontros presenciais, sendo que o último contou com a interação dos alunos na rede social facebook ${ }^{4}$. Neste espaço de convivência com o outro (MATURANA, 2002), procuramos estabelecer relações de respeito diante da diversidade de ideias a partir da interação entre os grupos, oportunizando diálogo e aprendizagem.

\section{Diálogos Teóricos}

Atualmente as Tecnologias Digitais (TD) estão cada vez mais presentes nos espaços de ensino, contudo, sabemos que a tecnologia por si só não desenvolve aprendizagem. As metodologias de ensino construtivistas, dentre elas o Ensino por Projetos (PORTES, 2010) aliado a práticas multidisciplinares, podem promover uma maior interação entre os envolvidos no processo de ensino e de aprendizagem. Segundo Portes (2010),

O desenvolvimento de projetos tem como objetivo, resolver questões relevantes para o grupo, gerar necessidades de aprendizagem, ou seja, tornar a aprendizagem ativa,

\footnotetext{
${ }^{3}$ Disponível em: MORALES, L. S. ; MARTINEZ, M. L. S. ; GAUTÉRIO, V. L. B. ; RODRIGUES, S. C. . Do papel à lousa digital: explorando conceitos geométricos com o Tangram. In: Débora Pereira Laurino; Daniel da Silva Silveira. (Org.). Projeto Novos Talentos: experiências com tecnologias no ensinar e aprender Matemática. 1ed.Rio Grande: Pluscom Editora, 2016, v. 1, p. 61-82.

${ }^{4} \mathrm{~A}$ rede social escolhida pela turma teve como propósito socializar as produções e realizar discussões, pois esta rede apresenta a opção de grupo fechado, ou seja, somente a turma, as professoras e a direção da escola têm acesso.
} 
interessante, significativa, real e atrativa para o aluno, englobando a educação em um plano de trabalho agradável, sem impor os conteúdos programáticos de forma autoritária. (PORTES, 2010, p.3)

No entanto, uma das maiores dificuldades e preocupação de alguns gestores ainda tem sido em reunir um grupo de professores, cada um em suas áreas específicas, para o planejamento de práticas a partir de um tema comum a todos. No entanto, as atividades multidisciplinares, por consistir na construção de um conhecimento sólido de um conjunto de disciplinas estudadas de maneira não-linear entre si, permitindo um conhecimento não especializado, mais polivalente e eclético pelo seu caráter lúdico possibilita o desenvolvimento de propostas pedagógicas em que as TD contribuam para o desenvolvimento de habilidades e competências nos estudantes.

Enquanto docentes, é importante nos questionarmos sobre a própria prática pedagógica, pois é partir destes que passamos a nos dar conta das nossas ações como docentes e assim pensar em algumas alternativas, neste caso, nos questionamos: Como desenvolver práticas multidisciplinares com o auxílio das TD? Neste cenário, o papel do professor, segundo Moran (2006) será de orientador/facilitador do processo de aprendizagem dentre eles interpretação de dados, articulação e contextualização dos mesmos.

No contexto educacional, algumas áreas do conhecimento como a Matemática são consideradas por muitos estudantes como o "bicho papão", parte da impressão por desses estudantes tem origem na própria cultura local, isto é, vem do ensino de casa, pois os próprios pais, muitas vezes, valorizam mais a disciplina de Matemática do que as demais, passando a exigir que os mesmos 'decorem' os conceitos e que os 'reproduzam' nas avaliações o que o professor procurou ensinar, para que possam ser 'alguém na vida', gerando assim uma fragilidade conceitual vivenciada por muitos estudantes, principalmente do Ensino Fundamental, que desconhecem conceitos geométricos básicos como ponto, reta, plano, entre outros. Conceitos que Escher, um admirador das formas e da transformação, explora em suas obras impregnadas pela lógica Matemática.

Segundo Moran (2006) os alunos são dotados de inteligências múltiplas e as atividades pedagógicas devem as despertar pela liberdade de colocar suas habilidades e competências a serviço da produção do conhecimento individual e coletivo. A Geometria aliada a metodologia de Ensino por Projetos (PORTES, 2010), em que os estudantes sejam ativos, se apresenta como uma ferramenta facilitadora dos processos de ensino e aprendizagem, oportunizando ao aluno a criação, construção, manipulação e descobertas, passando a contribuir para a construção do conhecimento. Neste contexto, o professor tem o papel de mediador, pois contribui para o desenvolvimento da aprendizagem significativa. Segundo 
Ausubel (1982), para se atingir uma aprendizagem significativa com base na compreensão do mundo, dos valores sociais e culturais, o professor precisa compreender, neste estudo a aprendizagem Matemática, como uma construção pessoal e ativa do educando. Assim, para que possamos vislumbrar a aprendizagem significativa, as novas informações precisam estar relacionadas com os conhecimentos prévios, desafios e situações vivenciadas.

As práticas multidisciplinares que apresentamos neste estudo, com a articulação entre Matemática e Artes tendem a intensificar o interesse por parte dos estudantes, em solucionar os desafios encontrados nas atividades de Matemática. Os PCNs abordam a relação da disciplina de Artes integrada a outras disciplinas curriculares:

A Arte tem uma função tão importante quanto à dos outros conhecimentos no processo de ensino e aprendizagem, [...]. Esta área favorece ao aluno relacionar-se criadoramente com as outras disciplinas do currículo. Um aluno que exercita continuamente sua imaginação estará mais habilitado, [...] a desenvolver estratégias pessoais para resolver um problema matemático. (BRASIL, 1998, p. 19).

Sendo assim, a utilização do Tangram ${ }^{5}$ e do software Geogebra ${ }^{6}$, além de possibilitar a integração entre Matemática e Artes, possibilita uma maior integração entre os envolvidos e

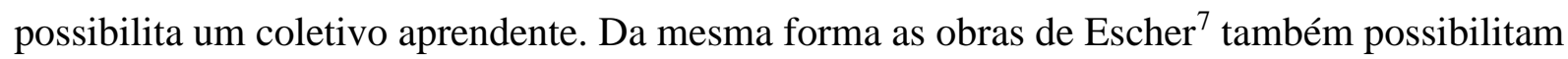
a integração entre as áreas do conhecimento, pois através das obras muitos conceitos geométricos e artísticos são explorados.

Os professores também poderão se valer das TD disponíveis para ensinar determinados conceitos e procedimentos, como no ensino de Matemática, possibilitando que os estudantes, nativos digitais (PRENSKY, 2001), aprendam através dos softwares, aplicativos e demais recursos tecnológicos aos quais possibilitam que os estudantes, em ritmos próprios e estilo de aprendizagem, construam seu conhecimento. Mendes (2009) corrobora ao colocar que o uso de softwares educativos permitem aos estudantes compreenderem e aprenderem os conceitos por meio da interação, visualização e da ação de fazer o que é proposto.

5 Na etimologia, o termo Tangram é oriundo da palavra inglesa tangam, que significa "misturas" ou "desconhecidos". Contudo, existem estudos que demonstram que a origem deste termo está associada à Dinastia Chinesa Tang, em que surgiu uma das lendas que envolvem este quebra-cabeça. Em chinês, o Tangram também é conhecido como as "Sete Peças Inteligentes".

6 Um programa capaz de realizar cálculos de álgebra / geometria e que possibilita construções geométricas. Disponível em https://www.geogebra.org/?lang=pt. Acesso 12 dez 2018.

7 Maurits Cornelis Escher foi um artista gráfico holandês conhecido pelas suas xilogravuras, litografias e meios-tons, que tendem a representar em suas obras o preenchimento regular do plano e transformações geométricas. 
Segundo Jacinto e Carreira (2017) o conhecimento matemático produzido através de atividades com papel e lápis é qualitativamente diferente daquele que é produzido com o uso do Geogebra devido as possibilidades que os softwares oferecem aos estudantes em observar determinadas situações possibilitando uma certa ação, essa ferramenta que 'convida' o indivíduo a realizar uma ação com ele. No entanto, as TD só poderão potencializar o ensino desde que sejam usadas pedagogicamente e não simplesmente usá-las sem definir o método.

\section{3 . Desenvolvimento: Elaboração das práticas multidisciplinares}

As atividades foram desenvolvidas com os estudantes de uma turma do $8^{\circ}$ ano de uma escola de Rio Grande/RS/Brasil, em um período de seis encontros, de duas horas, na qual os alunos sobre a orientação das professoras de Matemática ${ }^{8}$ e Artes, e ainda da auxiliar do laboratório de informática pesquisaram sobre as obras de Maurits Cornelis Escher, o qual "é sempre lembrado como um amante da Matemática" (BENEDITO EUGÊNIO, 2012, p. 01) e partiram para atividades práticas fundamentadas na experimentação, na investigação, no trabalho em grupo, na cooperação, na reflexão e socialização das atividades propostas.

No primeiro encontro, as professoras envolvidas e a responsável pelo laboratório de informática realizaram uma roda de conversa com os estudantes para apresentar o projeto, utilizando-se de uma apresentação em PowerPoint, discutiram sobre as propostas e exploraram alguns conhecimentos prévios dos alunos. Com a visualização das obras de Maurits Cornelis Escher problematizamos o uso/aplicação dos conceitos da Geometria presentes, como o ponto, a reta, o plano, os vértices, as diagonais e a classificação dos ângulos, além de simetria e isometria.

Os estudantes participaram da discussão, fizeram algumas anotações sobre os conceitos que estavam "no esquecimento" como colocou o Aluno 2. E ainda exploramos os procedimentos adequados para a utilização da régua, compasso e esquadros. No entanto, a Aluna 5 e Aluna 12 foram flagradas utilizando-se do smartphone. Ao serem questionadas sobre tal atitude explicaram que "Como não sabíamos as coisas que vocês estavam falando fomos pesquisar na internet." Situação nos leva a perceber que atualmente nossos estudantes

8 Professora da rede municipal de ensino cedida a Universidade Federal do Rio Grande - FURG devido a uma parceria com a Secretaria de Município da Educação (SMEd) que disponibilizou um professor de Matemática para atender as demandas de formação continuada no Laboratório de Educação Matemática e Física (LEMAFI) que constitui-se em um dos espaços vinculados ao Centro de Educação Ambiental, Ciências e Matemática (CEAMECIM) com o intuito de desenvolver ações de incentivo ao ensino, à pesquisa e extensão, integrando as áreas de Educação Matemática e Física. 
são nativos digitais (PRENSKY, 2001), já desenvolveram autonomia para o aprender pela pesquisa, devido ao fácil acesso a recursos tecnológicos e às informações que são do seu interesse, experienciando o aprender de forma única, assumindo a singularidade do ser humano. A rápida disseminação da TD provocou mudanças tão fundamentais e irreversíveis nesta nova geração que culminou na produção de um efeito de singularidade (PRENSKY, 2001).

Para a organização do cronograma das atividades discutimos com os estudantes as datas disponíveis, durante as aulas de Matemática e Artes, combinamos quais as tarefas seriam realizadas com uma ou outra professora, sendo que a responsável pelo laboratório estaria presente em todas as atividades que envolvessem as Tecnologias Digitais. No final do projeto, faríamos um seminário com as duas professoras no qual os estudantes apresentariam suas produções através de alguma ferramenta digital (PowerPoint, vídeo, livro digital, etc). Para Soldera (2013) nessa maneira diferenciada de ensinar desperta o interesse dos alunos, pois em muitas situações os alunos encontram-se entediados da maneira como o professor conduz a aulas, porém se mudarmos a metodologia, contextualizarmos o ensino da matemática, principalmente com os temas estudados em outra disciplina, os mesmos se empolgam e querem participar dos desafios. Porém, destacamos que contextualizar o ensino permite que o aluno construa conceitos na contextualização, mas os estudantes precisam perceber que a partir da descontextualização é que poderão considerá-los em outros contextos. (SPINELLI, 2011).

O segundo encontro, foi com a professora de Matemática e a responsável pelo laboratório. Partimos pela pesquisa sobre a origem do Tangram e seu potencial para o aprendizado de Geometria. De acordo com o Aluno 4 " Ele é lúdico e pedagógico o que faz com que os alunos aprendam brincando"; a Aluna 15 comentou que "Com o Tangram podemos estudar formas geométricas, simetria, frações, divisão, área, perímetro, medidas, congruência, semelhança, ângulos da figura e tudo que a professora quiser" e o Aluno 7 afirma "Tangram é um quebra cabeça chinês formado por sete peças que é 5 triângulos, 1 quadrado e 1 paralelogramo.". Logo em seguida, perceberam que existem outras formas de representação do jogo, como circular, coração partido, oval e quadrada, que é a forma escolhida para trabalharmos no momento.

Então partimos para a ação. Os estudantes receberam uma folha de oficio e foram convidados a construir um Tangram somente com a dobradura, estavam proibidos de usar régua. Curiosos, pegaram a folha e ficaram à espera das instruções da professora. Começamos construindo um quadrado $\mathrm{ABCD}$ e marcamos os pontos $\mathrm{A}, \mathrm{B}, \mathrm{C}$ e $\mathrm{D}$ nos vértices do quadrado 
formando os quatro segmentos de reta. Neste momento aproveitamos para discutimos as diferenças entre retas, segmentos de reta e semirretas.

Continuamos representando a diagonal do quadrado $\mathrm{ABCD}$, encontrando o ponto médio desta e marcando o ponto E para traçar o segmento que começa em D e vai até E. e assim sucessivamente, construímos um Tangram com as seguintes peças: dois triângulos grandes, um triângulo médio, dois triângulos pequenos, um paralelogramo e um quadrado. Aproveitamos a atividade para dialogar sobre os conceitos de ângulos, são eles: Colaterais Internos e externos; Colaterais Adjacentes e Correspondentes; Alternos Internos e Externos; Opostos pelo Vértice; entre outros. Em seguida, com o Tangram pronto, a proposta é colorir cada peça e após recortar, a fim de construir diferentes figuras.

No decorrer das atividades, ao manipular as sete peças do jogo, os estudantes desenvolvem percepções que envolvem a sinestesia, isto é, a visão e o tato. Segundo Dorin (1982, p.183), “As percepções visuais, aditivas e táteis decorrem do interrelacionamento entre capacidade inata, maturação e aprendizagem.”.

Outra atividade foi visualizar as frações representadas pelas partes do jogo, pois cada uma das peças do Tangram é uma parte do todo. Se os dividir em 16 triângulos correspondentes ao triângulo pequeno podemos estabelecer uma relação entre todas as figuras em função do triângulo pequeno que equivale a 1/16 do Tangram (quadrado completo com as 7 peças). As atividades com o jogo além de oferecer a socialização, ainda, provocaram o conflito sócio cognitivo que, de acordo com Lorenzato (2012), propicia ao professor uma fonte preciosa de informações a respeito do que os alunos conhecem, como e o que estão aprendendo, como pensam e como estão evoluindo.

No terceiro encontro os estudantes ficaram com a professora de Artes, a qual buscou aprofundar as pesquisas sobre as obras de Escher, as quais os estudantes deveriam utilizar-se do editor de textos para organizar um artigo através da revisão bibliográfica sobre o tema " $\mathrm{A}$ geometria presente nas as obras de Escher" e aprofundar a análise de pelo menos uma das obras, e ainda fazer a releitura utilizando lápis, papel, régua entre outros, ou alguma ferramenta digital.

As práticas pedagógicas de Arte devem estar norteados por três eixos: produzir, apreciar e contextualizar. Através do "produzir" o aluno se expressa, experimentando as linguagens artísticas. Apreciando, analisando algumas produções, sejam suas ou dos colegas, entra em contato com a produção histórica e social da Arte. Segundo os PCN (1998)O estudo, a análise e a apreciação da arte podem contribuir tanto para o processo pessoal de criação dos 
alunos como também para sua experiência estética e conhecimento significado que ela desempenha nas culturas humanas. (p. 49).

Percebemos que ao trazer atividades diversificadas para o Ensino da Matemática e da Arte despertamos o interesse dos estudantes e os encorajamos a questionar-se e pesquisar, cooperar e colaborar com o grande grupo formando um coletivo aprendente, para dar conta dos desafios encontrados, não somente para as atividades do projeto, mas nas diversas disciplinas.

O quarto dia de trabalho contamos com a professora de Matemática, no qual os estudantes fizeram uma breve apresentação das atividades realizadas na aula de Artes e procuramos aprofundar a análise dos artigos, ou seja, analisar de pelo menos uma das obras buscando compreender a presença da Geometria. Observou- se que os estudantes estavam compreendendo a atividade e fazendo a análise de forma adequada, no entanto a dificuldade estava no escrever, expressar-se através da escrita, esses por sua vez passaram a buscar uma formalidade para além de seus conhecimentos o quê dificultou a escrita das suas próprias compreensões.

O uso do editor de textos também não é uma tarefa fácil, pois os nativos digitais (PRENSKY, 2001) crescem em meio às tecnologias digitais, aprendendo a acessar de forma rápida uma gama imensa de informações; zapeiam entre os diversos espaços virtuais que julgam interessantes ou úteis (VEEN; VRAKKING, 2009), no entanto um editor de textos, as ferramentas para formatar o texto conforme as normas da Associação Brasileira de Normas Técnicas (ABNT) são tarefas desconhecidas deste público. Podemos dizer que os estudantes precisaram desenvolver habilidades, ou seja, aprender a fazer fazendo.

Nos chama a atenção a fala do Aluno 6, que colocou "[...] queres que eu te ajude? Eu tenho um tablete que ganhei da tia, mas não tenho internet na minha casa, ai eu fico mexendo e aprendi a escrever nele. Sei usar a régua, colocar espaços e tudo isso que tem que fazer.". A partir deste momento, aquele menino que de certa forma se sentia 'diferente' por não dialogar sobre o uso da TD com os demais colegas passa a se sentir 'útil', circula na sala para explicar o procedimento aos colegas. E logo se escuta: "assim as aulas são bem melhores, era aquela coisa robótica, agora a gente pode conversar para ajudar e pedir coisas e caminhar pela sala, fazer muitos amigos, porque o projeto uniu os alunos, ficou muito bom”. (Aluno 6).

Percebemos diferentes emoções que especificam diferentes domínios de ações, que estão constituídas em domínios de ações que são o da colaboração e a do compartilhamento, em coordenações de ações que implicam a aceitação do outro como um legítimo outro na convivência, formando comunidades sociais (MATURANA, 2002). 
RELACult - Revista Latino-Americana de Estudos em Cultura e Sociedade

Revista Latinoamericana de Estudios en Cultura y Sociedad | Latin American Journal of Studies in Culture and Society 10 V. 05, ed. especial, abr., 2019, artigo ${ }^{\circ} 1253$ | claec.org/relacult |e-ISSN: 2525-7870

O projeto transformou a sala de aula em um espaço educativo amoroso com escuta, acolhimento e respeito ao outro, condição percebida não apenas pelos professores, mas especialmente pelos estudantes. "Agora a aula me deixa mais animado e gostando da escola onde estou estudando sem ter dúvidas que este é o melhor jeito de aprender" (Aluno 13). Esse comentário representa o novo momento vivido; reflete um novo emocionar, o encontro com o outro.

O quinto e sexto encontro, com a professora de Artes, os estudantes tinham que entregar a releitura das obras de Escher escolhidas, explorar o software Geogebra para a construção de elementos geométricos que lembrem/representem a obra utilizada para a releitura ou sua releitura, caso achassem mais interessante e disponibilizar suas produções, dentre elas: as releitura das obras de Escher e as representações geométricas construídas no Geogebra, no grupo do Facebook nomeado "Internaltas da Matemática 2018”. Tal proposta objetivou uma maior interação entre os envolvidos, bem como, compartilhamento de saberes em diferentes espaços, dentre eles: na escola durante as aulas e pelo grupo do Facebook.

O Geogebra é um software que permite a exploração e simulação, espaço que permitiu simular e recriar as obras escolhidas. Quando construíam um procedimento, comprovavam, com o apoio dos colegas encontravam seus erros, corrijam, consertavam, refaziam e procuravam adequações. De acordo com Cruz (2005);

[...] a compreensão dos conceitos geométricos é favorecida quando estes são explorados num ambiente dinâmico e interativo, pois, tal ambiente, configura-se num recurso que pode possibilitar a transição entre o conhecimento que o aluno já acumula e a facilidade para conjecturar que o computador proporciona. (CRUZ, 2005, p.17).

O seminário final contou com a presença das duas professoras e mais da responsável pelo laboratório, pois esta os acompanhou durante todo o projeto e fez parte da banca, ou seja, participou das avaliações finais. Trabalhos com projetos que pressupõe pesquisa e produções não podem ser avaliadas em um momento único, mas a cada evolução, pois o processo é mais interessante que o produto final. Assim, cada professora avaliou os momentos que participou e a colega do laboratório avaliou as produções no todo. Devemos também destacar que, em nenhum momento dissemos que o trabalho era individual ou em grupos, os estudantes foram se organizando e reorganizando de acordo com as suas necessidades ou escolhas pessoais.

Durante a socialização da pesquisa, alguns apresentaram slides elaborados pelo grupo ou apresentaram vídeos que caracterizavam a pesquisa. A socialização com todos os colegas da sala de aula não foi apenas informativa, foi também colaborativa, pois a projeto no seu 
todo propiciou o espaço de discussão e os colegas contribuíram com as pesquisas apresentadas pelos colegas.

O coletivo aprendente, no final do seminário, concluiu que o projeto aproximou os conceitos abordados na sala de aula ao cotidiano, as linguagens de programação e comunicação da sociedade informatizada, e ainda, contribuíram para a produção de novas formas de interação entre os conceitos. Percebemos que projetos em que os alunos são ativos, participando de todas as etapas do processo, combinado diferentes ferramentas e recursos didáticos desenvolvem a criatividade, o aprender a pesquisar de forma crítica e responsável, os forma para a cidadania.

\section{1 Desenvolvimento: Análise e discussão da prática multidisciplinar}

Neste artigo, temos como objetivo discutir, refletir e ressignificar, conceitos geométricos a partir de práticas multidisciplinares, as quais procuramos nos deter em atividades lúdicas as quais contribuíram para que os estudantes resinificassem os conceitos matemáticos com auxílio das tecnologias digitais, bem como refletir sobre a construção de Geometria e Artes presentes nas atividades propostas.

Percebemos que os estudantes quando desafiados a desenvolver uma determinada atividade lúdica, apoiada em outras áreas do conhecimento, passam a interagir, pois as práticas multidisciplinares, motivam os estudantes a buscar possíveis soluções quando desafiados, também refletem sobre determinados conceitos e buscam embasamento para dar conta da atividade, potencializando o desenvolvimento da habilidades para pesquisa e criticidade para analisar/selecionar as informações encontradas, principalmente na web.

Neste caso, para a construção do Tangram com dobraduras, as releituras das obras de Escher e representações geométricas no software Geogebra, foi preciso revisitar os principais conceitos geométricos, de acordo com as necessidades do grupo, para que pudessem avançar na atividade proposta contribuindo para que novas descobertas pudessem emergir a partir pesquisa, do raciocínio lógico Matemática e através da criatividade. Nesse sentido, para D’Ambrósio (1996, p.73) “partir para a prática é como um mergulho no desconhecido. Pesquisar é o que permite a interface interativa entre teoria e prática”. Nesse processo, o indivíduo parte para a prática tomando como base um conhecimento teórico e busca através da pesquisa as devidas relações com o seu contexto.

\section{Conclusões}


As práticas multidisciplinares desenvolvidas pelos estudantes, tem contribuído para uma melhor compreensão de determinados conceitos de Geometria e Artes através das TD e assim tem ampliado a produção do conhecimento dos estudantes através da ludicidade, autonomia e da criatividade no desenvolvimento da proposta pedagógica. Esta proposta fez com que os estudantes desenvolvessem novas compreensões sobre os conceitos geométricos presentes no nosso dia a dia e vistos nas primeiras aulas, bem como puderam construir o Tangram e assim explorar outros conceitos geométricos. Além disso, foi possível perceber uma maior interação entre os colegas, ao pesquisarem na Internet, nos livros didáticos sobre o tema: Tangram e obras de Escher.

No entanto, alguns alunos tiveram dificuldades em desenvolver a atividade no software, por terem pouco contato com o computador, o que ocasionou um tempo maior de manipulação a fim de conhecer os principais comandos do software para que após a manipulação pudessem realizar a atividade multidisciplinar.

Assim, ao professor mediador da prática fica o desafio de trabalhar com as tecnologias digitais. Estudos (MISKULIN, 2012; LORENZATO, 2012; SCHEFFER, 2012) apresentam a importância de inserirmos a tecnologia na Educação Matemática. Esta assume cada vez mais um papel fundamental na construção, geração e disseminação do conhecimento, ultrapassando a perspectiva de tecnologia voltada para o uso apenas como mais um recurso. Segundo Lorenzato (2012) alguns professores sentem inseguros em realizar qualquer trabalho com o uso da TD, seja porque consideram que sua formação foi deficiente nesse campo, quer por haver até entre eles quem jamais a tenha estudado em qualquer nível de escolaridade. No entanto, o que precisamos é nos preparar e nos entendermos como aprendizes, superando os contratempos juntamente com os estudantes.

O estudo, evidenciou que o desenvolvimento de práticas multidisciplinares a luz da ludicidade, contribui para a produção de novos conhecimentos sobre diferentes temas as quais a Matemática e Artes, no desenvolvimento da prática no software, desenvolvem a criatividade, o raciocínio lógico, a percepção espacial e visual e assim passam a aprender a pesquisar de forma crítica ressignificam os saberes sobre determinados conceitos.

\section{Referências}

AUSUBEL, D. P. A aprendizagem significativa: a teoria de David Ausubel. São Paulo: Moraes, 1982.

BENEDITO E; TIAGO J. Um olhar evolucionista para a arte de M. C. Escher.Ciênc. cogn. Rio de Janeiro, v. 17, n.2,p. 63-75,set. 2012 . Disponível em 
<http://pepsic.bvsalud.org/scielo.phpscript=sci_arttext\&pid=S180658212012000200007\&lng $=$ pt\&nrm=iso $>$. acessos em 07 jan. 2019.

BRASIL, Ministério da Educação e do Desporto, Secretaria de Educação Fundamental. Parâmetros curriculares nacionais. Brasília: MEC/SEF, 1998.

CRUZ, D. G. da; A utilização de Ambiente Dinâmico e Interativo na construção do conhecimento produzido. 169 p. Tese ( Mestrado em Educação Matemática) - Setor de Ciência Humanas e Sociais, Universidade Federal do Paraná, Curitiba, 2005.

D’AMBROSIO, U. Educação Matemática: Da teoria a prática. - Campinas, SP: Papirus, 1996.

DORIN, L. Psicologia do Desenvolvimento. 4 ed. São Paulo: Brasil, 1982.

FAZENDA, I C. A. (org). O que é interdisciplinaridade? - 2 ed. São Paulo: Cortez, 2013.

JACINTO, H; C, S. Diferentes Modos de Utilização do GeoGebra na Resolução de Problemas de Matemática para Além da Sala de Aula: evidências de fluência tecnomatemática.Bolema, Rio Claro, v. 31,n. 57,p. 266-288, Apr. 2017. Available from $<$ http://www.scielo.br/scielo.phpscript=sci_arttext\&pid=S0103636X2017000100015\&lng=en \&nrm=iso>. Access on 07 Jan.2019. http://dx.doi.org/10.1590/1980-4415v31n57a13.

LORENZATO, S. O Laboratório de ensino de Matemática na formação de professores. -3. Ed. - Campinas, SP. Autores Associados, 2012.

MATURANA. H. A Ontologia da Realidade. Belo Horizonte: Ed. UFMG, 2002.

MENDES, I. A. Matemática e investigação em sala de aula. Tecendo redes cognitivas na aprendizagem. São Paulo: Livraria da Física, 2009.

MORAN, J. M. Novas tecnologias e mediação pedagógica. Ed. Papirus, 12 ed. 2006.

NOGUEIRA, M. O. G.; LEAL, D. Teorias da aprendizagem: um encontro entre os pensamentos filosófico, pedagógico e psicológico. Curitiba: Intersaberes, 2015.

PRENSKY, M. Digital natives, Digital Immigrants. On the Horizon. Vol. 9, Nº.5, 2001.

PORTES, K. A. C. A organização do currículo por projetos de trabalho. Artigo publicado em: http://www.ufjf.br/virtu/files/2010/04/artigo-2a3.pdf Acesso em 05 jan. 2019.

ROGENSKI, M.L.C; PEDROSO, S.M.D. O ensino da Geometria na educação básica: realidade e possibilidades, 2014.2 Disponível em <http://www.diaadiaeducacao.pr.gov.br/portals/pde/arquivos/44-4.pdf>. Acesso em 21 set 2018.

SOLDERA, L. A contextualização no ensino da matemática: um olhar a partir do entendimento de professores de matemática. Trabalho de Sistematização do Curso em Matemática - Licenciatura UNIJUÍ. Ijuí, RS, 2013.

SPINELLI, W. A construção do conhecimento entre o abstrair e o contextualizar: o caso do ensino da Matemática. 2011. 138 p. Tese (Doutorado) - Faculdade de Educação, $\mathrm{U}$ 